\title{
Pituitary apoplexy
}

\author{
Daisuke Yamada MD, Tatsuya Fujikawa MD PhD
}

Cite as: CMAJ 2018 December 3;190:E1419. doi: 10.1503/cmaj.180658

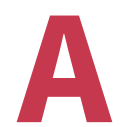

previously healthy 50-year-old man attended the hospital outpatient clinic room, having been unwell for 5 days. He had experienced sudden-onset headaches and impairments in visual accommodation intermittently during the previous month, but these symptoms improved spontaneously. On the day of admission, the patient collapsed in the waiting room of the outpatient clinic. His blood pressure was $83 / 65 \mathrm{~mm} \mathrm{Hg}$, and his blood glucose level was 1.11 (normal 4.4-10.0) $\mathrm{mmol} / \mathrm{L}$. He regained consciousness following a glucose injection. Computed tomography (CT) (Figure 1) and magnetic resonance imaging (MRI) of the head (Appendix 1, available at www.cmaj.ca/lookup/suppl/doi:10.1503/ cmaj.180658/-/DC1) showed enlargement of the pituitary gland and subacute bleeding, indicative of pituitary apoplexy. Following admission, the patient had no further impairment of consciousness, possibly owing to steroid replacement therapy, which was started to treat his hypotension, cortisol deficiency and hypoglycemia. He was diagnosed with panhypopituitarism with secondary adrenal insufficiency. Outpatient follow-up has been uneventful.

Pituitary apoplexy is an acute clinical syndrome caused by hemorrhage or infarction of the pituitary gland, which typically occurs within a pituitary adenoma. ${ }^{1-3}$ In those with an adenoma, trauma, pregnancy, hypertension, cardiac surgery, anticoagulant therapy and treatment with dopamine agonists may increase the risk. ${ }^{2,3}$ Typical symptoms include loss of vision, endocrine abnormalities and severe headache. ${ }^{1-3}$

The clinical presentation of pituitary apoplexy can be acute or slowly progressive (subacute), depending on the extent of bleeding, edema and necrotic evolution. ${ }^{4}$ Most patients with a mild, stable clinical condition - including those with isolated ocular palsies - can receive conservative management. ${ }^{3,4}$

The diagnosis is based on a combination of clinical assessment, endocrine abnormalities and radiologic findings (CT and $\mathrm{MRI}){ }^{2,3}$ and the differential diagnosis includes subarachnoid hemorrhage and bacterial meningitis., ${ }^{2,3}$ Sudden signs of neuroophthalmic deterioration (e.g., loss of vision) or impaired consciousness are a surgical emergency. ${ }^{1-3}$ Although symptoms of pituitary apoplexy may improve spontaneously, delayed diagnosis may lead to severe endocrine complications.

Patients with suspected hypoadrenalism should begin empirical steroid therapy with hydrocortisone. ${ }^{1,3}$

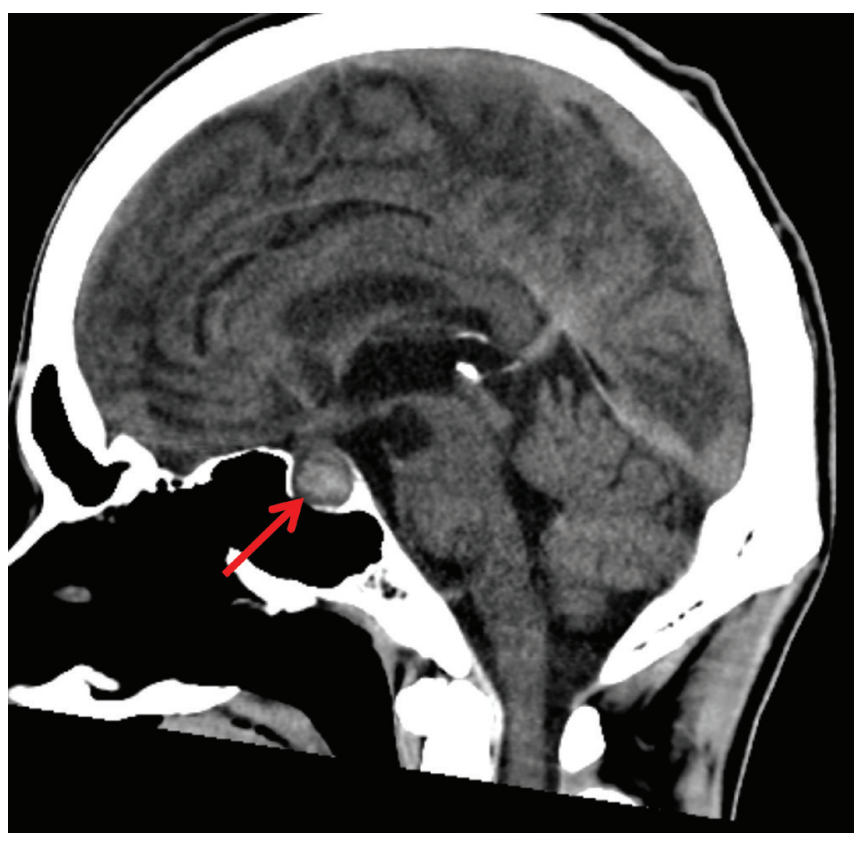

Figure 1: Sagittal computed tomography scan in a 50-year-old man showing an enlarged, hyperdense mass in the pituitary (arrow).

\section{References}

1. Bajwa R, Kaur PP, Paluzzi A. Headaches and hormones: a potentially lethal combination. BMJ 2016;352:h6752.

2. Ishii M. Endocrine emergencies with neurologic manifestations. Continuum (Minneap Minn) 2017;23:778-801.

3. Rajasekaran S, Vanderpump M, Baldeweg S, et al. UK guidelines for the management of pituitary apoplexy. Clin Endocrinol (Oxf) 2011;74:9-20.

4. Goyal P, Utz M, Gupta N, et al. Clinical and imaging features of pituitary apoplexy and role of imaging in differentiation of clinical mimics. Quant Imaging Med Surg 2018;8:219-31.

Competing interests: None declared.

This article has been peer reviewed.

The authors have obtained patient consent.

Affiliations: The Post-graduate Education Center (Yamada); Department of General Internal Medicine (Fujikawa), Mitoyo General Hospital, Kan'onji, Kagawa, Japan

Acknowledgement: The authors thank Dr. Fumio Otsuka, Department of General Medicine, Okayama University Graduate School of Medicine, Dentistry and Pharmaceutical Sciences, for useful discussions.

Correspondence to: Tatsuya Fujikawa. tfujikawa-gi@umin.ac.jp 